\title{
Editorials
}

\section{BSHG is born}

Medical genetics has a long and honourable history in the United Kingdom where some of the very earliest genetics clinics and laboratory applications of genetic diagnostic techniques have been developed. Organisationally, however, those involved in the application of genetics to health care in the UK have been somewhat balkanised. The Clinical Genetics Society was founded in 1970, with almost entirely medical membership, and cytogeneticists without medical qualifications founded an independent Association of Clinical Cytogeneticists in 1976. Subsequently, genetic associates formed the Genetic Nurses and Social Workers Association in 1980 (its name recently changed to the Association of Genetic Nurses and Counsellors) and the Clinical Molecular Genetics Society was founded in 1988.

It has long been obvious that the application of genetics to medical care requires a closely integrated and interactive team involving scientists, doctors, genetic associates, administrators, and others. There are some specific issues relating, for example, to training, accreditation, pay and career structure, and audit which need to be dealt with separately by different professional groups. There are other broad and important areas of practice and policy in which common interests between the groups are much greater than their separate interests. The reality on the ground, in the UK and in many other places, has been that genetics has predominantly been practised in such multidisciplinary settings in integrated Regional Genetic Centres. The continuing division of the national community into separate subsections, although it has been significantly blurred and softened with the passage of years, has for some time seemed an historical anomaly.
An important step towards strengthening the scientific and professional life of those associated with applications of genetics to health care was taken with the formation, on 1 January 1996, of the British Society for Human Genetics. This is effectively a federation of the four previous organisations, with agreement to hold joint meetings, use common administrative structures, and make common statements on policy and issues of public concern. The new organisation will start with approximately 1200 members, and is likely to be a powerful voice on the national scene. It will also give the UK, for the first time, a single conduit for entering into discussion, collaboration, and agreements with national societies in other countries.

As a lead in to closer integration, a joint annual conference has been held for several years. This was attended in 1994 by 396 people and in 1995 by 625 . If these two points represent a trend, the current membership of BSHG will grow rapidly, to the benefit of all concerned. The founding Chairman of the BSHG is Professor Andrew Read, Professor of Human Genetics at the University of Manchester. With a background in general genetics and molecular genetics, and a wide knowledge of all other branches of the profession, Andrew Read is a strong, highly respected, and unifying figure to lead this new venture. He was one of several people who showed wise leadership in transcending the narrow interests of specific groups for the wider interests of the genetics community as a whole, and insisted on finding ways of solving the many small problems that always lie in the path of those giving up a small degree of their own sovereignty. The new Society is in good hands and is certain to prosper.

MARTIN BOBROW 